\title{
Retrospective Environment Carrying Capacity Assessment and Comparison for Marine Reclamation
}

\author{
Mingchang Li ${ }^{1}$, Jingguo Zhang² \\ ${ }^{1}$ Laboratory of Environmental Protection in Water Transport Engineering, Tianjin Research Institute of Water \\ Transport Engineering, Tianjin, China \\ ${ }^{2}$ Tianjin Oceanic Administration, Tianjin, China \\ Email: Imcsq1997@163.com
}

Received December 2013

\begin{abstract}
For improving the managed level and guiding the environmental management of reclamation engineering, a synthetic assessment method based on cloud theory is applied to evaluate the environment carrying capacity of part of Tianjin Port in this paper. This retrospective assessment of carrying capacity aims to obtain the historical development situation of reclamation domain. The research is meaningful and efficient for judging the feasibility of marine reclamation.
\end{abstract}

\section{Keywords}

Retrospective; Environment Carrying Capacity; Assessment; Reclamation; Cloud Theory

\section{Introduction}

Recently, marine reclamation has resulted in the pollution of water environment and the destruction of ecological system. The environmental and ecological problem is the important restricting factor for regional sustainable development. How to evaluate the environmental impact of marine reclamation is very important for managing and guiding the district development scientifically.

Tianjin Port is an important port in our country. The rapid development of Tianjin Port results in more demand of marine resources, especially the land resource. So a new reclamation planning has been studied and presented to solve the problem of development space, namely Ergangdao Island. But the Tianjin Port locates in the west of Bohai Bay, the environmental impact is the key problem for deciding the feasibility of Ergangdao Island reclamation. So the historical environment situation of this district must be studied to obtain the basic condition of reclamation.

A basic assessment problem exists in this research. The characteristic of assessment is a combined process between assessment factors and assessment standard. So many assessment methods have been proposed and applied to many fields including ocean water quality and carrying capacity, such as Individual and comprehensive index method, fuzzy comprehensive evaluation method (Qian, 2006), grey clustering method (Feng, Wang, \& 
Zhang, 2000), matter element model analysis method (Pan, Fu, \& Liang, 2002), projection pursuit method (Wang, 2011), artificial neural network method (Chen \& Li, 2005) and nonlinear set pair analysis method (Li, Zhang, \& You, 2010), but several defects exist in these methods (Li \& Liu, 2009).

In this paper, a synthetic assessment method, namely cloud theory ( $\mathrm{Li} \& \mathrm{Du}, 2005$ ) is applied to evaluate the historical situation in Tianjin district, based on the characteristic of randomness and ambiguity. The research results show the situation of reclamation district and the efficiency of this method.

\section{Assessment Method}

\subsection{Cloud Theory}

Based on probability and fuzzy mathematic, the basic algorithm of cloud theory is to build an uncertainty transformation model for the exchange between concept and quantity. The cloud theory model has been applied to system evaluation, algorithm improvement, decision support, intelligent control, data mining, knowledge discovery and network security (Fu, Li, \& Wang, 2011).

\subsection{Procedure of Cloud Theory Assessment Method}

The randomness and ambiguity of concept can reacted in cloud theory by the mathematical expectation, entropy and hyper entropy. The detailed assessment procedure has seven steps (Li, Zhang, Si, Liang, \& Sun, 2012).

\section{Case Study}

Tianjin Port is an important support for district economy development. A new reclamation planning named that Ergangdao Island is proposed to improve the land resource for the rapid development of Tianjin Port and the demand of marine resources. In this research, the historical environment situation of this district is studied for obtaining the basic condition of reclamation and judging the feasibility of Ergangdao Island reclamation. Marine reclamation of Ergangdao Island is shown in Figure 1.

The grey section in Figure 1 is the panning reclamation of Ergangdao Island.

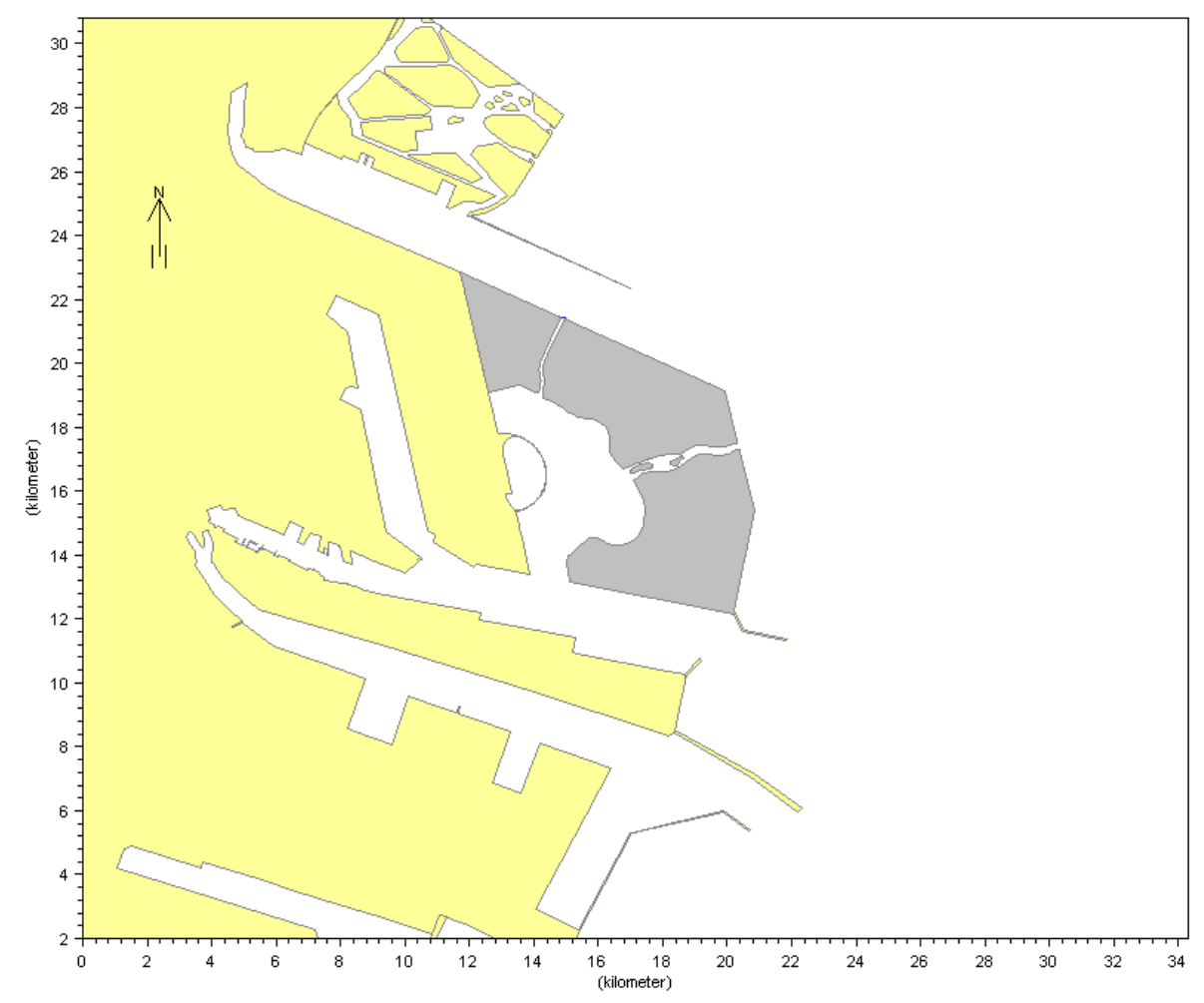

Figure 1. The location of Ergangdao Island. 


\subsection{Basic Situation of Reclamation Domain}

The total area of Tianjin marine is about $15,900 \mathrm{~km}^{2}$. It is very shallow and its averaged water depth is less than $20 \mathrm{~m}$. The sea bottom is very flat and its mean slope is less than $2 \%$.

\subsection{Assessment Indexes of Environment Carrying Capacity}

Thirteen assessment indexes (Suspended Substance (SS), COD, DO, DIN, Phosphate (Ph), Petroleum (Pe), Hg, $\mathrm{As}, \mathrm{Cu}, \mathrm{Zn}, \mathrm{Cd}, \mathrm{Pb}$ and $\mathrm{Cr}$ ) in marine waters, ten assessment indexes (Organic Carbon (OC), Sulfide (Su), Petroleum (Pe), $\mathrm{Hg}, \mathrm{As}, \mathrm{Cu}, \mathrm{Zn}, \mathrm{Cd}, \mathrm{Pb}$ and $\mathrm{Cr}$ ) in sediment and five assessment indexes (Chl, Phytoplankton (Pp), Zooplankton (Zp), Benthos (Be) and Intertidal benthos (Ib)) are selected for evaluating the current situation of engineering marine district. In this paper, single factor carrying capacity and multiple factors comprehensive carrying capacity are studied for evaluating the historical situation of reclamation domain from multiple angles.

\subsection{Assessment Levels of Environment Carrying Capacity}

The assessment standard of the whole indexes is used to evaluate retrospective environment carrying capacity listed in Table 1.

Table 1. Level standards of assessment index.

\begin{tabular}{|c|c|c|c|c|}
\hline \multirow{2}{*}{ Assessment indexes } & \multicolumn{4}{|c|}{ Level standards } \\
\hline & Good (I) & General (II) & Poor (III) & Very poor (IV) \\
\hline SS & $0-10$ & $10-100$ & $100-150$ & 150-Max ${ }^{1}$ \\
\hline COD & $0-2$ & $2-3$ & $3-4$ & 4-Max² \\
\hline DO & $\operatorname{Max}^{3}-6$ & $6-5$ & $5-4$ & $4-3$ \\
\hline DIN & $0-0.2$ & $0.2-0.3$ & $0.3-0.4$ & $0.4-\mathrm{Max}^{4}$ \\
\hline $\mathrm{Ph}$ & $0-0.015$ & $0.015 \sim 0.03$ & $0.03 \sim 0.045$ & $0.045-\mathrm{Max}^{5}$ \\
\hline $\mathrm{Pe}$ & $0-0.05$ & $0.05 \sim 0.3$ & $0.3 \sim 0.5$ & $0.5-\mathrm{Max}^{6}$ \\
\hline $\mathrm{Hg}$ & $0-0.05$ & $0.05 \sim 0.2$ & $0.2 \sim 0.5$ & $0.5-\mathrm{Max}^{7}$ \\
\hline As & $0-20$ & $20-30$ & $30-50$ & $50-\mathrm{Max}^{8}$ \\
\hline $\mathrm{Cu}$ & $0-5$ & $5-10$ & $10-50$ & $50-\mathrm{Max}^{9}$ \\
\hline $\mathrm{Zn}$ & $0-20$ & $20-50$ & $50-100$ & $100-\mathrm{Max}^{10}$ \\
\hline Cd & $0-1$ & $1 \sim 5$ & $5 \sim 10$ & $10-\mathrm{Max}^{11}$ \\
\hline $\mathrm{Pb}$ & $0-1$ & $1 \sim 5$ & $5 \sim 10$ & $10-\operatorname{Max}^{12}$ \\
\hline $\mathrm{Cr}$ & $0-50$ & $50-100$ & $100-200$ & $200-\mathrm{Max}^{13}$ \\
\hline OC & $0-2$ & $2-3$ & $3-4$ & $4-\mathrm{Max}^{14}$ \\
\hline SU & $0-300$ & $300-500$ & $500-600$ & $600-\mathrm{Max}^{15}$ \\
\hline Pe & $0-500$ & $500-1000$ & $1000-1500$ & $1500-\mathrm{Max}^{16}$ \\
\hline $\mathrm{Hg}$ & $0-0.2$ & $0.2-0.5$ & $0.5-1.0$ & 1.0-Max ${ }^{17}$ \\
\hline As & $0-20$ & $20-65$ & $65-93$ & $93-\operatorname{Max}^{18}$ \\
\hline $\mathrm{Cu}$ & $0-35$ & $35-100$ & $100-200$ & $200-\mathrm{Max}^{19}$ \\
\hline $\mathrm{Zn}$ & $0-150$ & $150-350$ & $350-600$ & $600-\mathrm{Max}^{20}$ \\
\hline $\mathrm{Cd}$ & $0-0.5$ & $0.5-1.5$ & $1.5-5$ & $5-\mathrm{Max}^{21}$ \\
\hline $\mathrm{Pb}$ & $0-60$ & $60-130$ & $130-250$ & 250-Max ${ }^{22}$ \\
\hline $\mathrm{Cr}$ & $0-80$ & $80-150$ & $150-270$ & $270-\mathrm{Max}^{23}$ \\
\hline Chl & $0-2$ & $2-5$ & $5-10$ & $10-\mathrm{Max}^{24}$ \\
\hline Pp & $0-25$ & $25-50$ & $50-150$ & $150-\mathrm{Max}^{25}$ \\
\hline $\mathrm{Zp}$ & $\operatorname{Max}^{26}-3$ & $3-2$ & $2-1$ & $1-0$ \\
\hline $\mathrm{Be}$ & $\operatorname{Max}^{27}-3$ & $3-2$ & $2-1$ & $1-0$ \\
\hline $\mathrm{Ib}$ & $\operatorname{Max}^{28}-3$ & $3-2$ & $2-1$ & $1-0$ \\
\hline
\end{tabular}

Note: $\mathrm{Max}^{1}-\mathrm{Max}^{28}$ is the max value of water quality measurement data owing to not be obtained by the water quality standard. 


\subsection{Results Analysis}

Following the assessment steps of cloud theory, the single factor and multiple factors method are applied to evaluate the water quality, sediment, ecology and comprehensive level in Table 2-8.

From the assessment results in Table 2-3, the water quality is good in 2010 and 2012. But the Phosphate is poor in the research years.

The sediment quality is good in 2010 and 2012 shown in the Table 4 and Table 5. Especially 2010, all the indexes are the level I.

The level of ecology indexes is poor (III) in 2010 and 2012.

The comprehensive assessment results show the level is acceptable.

\section{Conclusion}

In this paper, a synthetic assessment method based on cloud theory is applied to evaluate the marine reclamation

Table 2. Assessment results of water quality in 2010.

\begin{tabular}{ccc}
\hline \multirow{2}{*}{ Assessment indexes } & \multicolumn{2}{c}{ Assessment level } \\
\cline { 2 - 3 } & Single factor & Multiple factors \\
\hline SS & II \\
COD & II \\
DO & I \\
DIN & III \\
Ph & II \\
Pe & I \\
Hg & II \\
As & I \\
$\mathrm{Cu}$ & I \\
$\mathrm{Zn}$ & I \\
$\mathrm{Cd}$ & I \\
$\mathrm{Pb}$ & II \\
$\mathrm{Cr}$ & I \\
\hline
\end{tabular}

Table 3. Assessment results of water quality in 2012.

\begin{tabular}{ccc}
\hline \multirow{2}{*}{ Assessment indexes } & \multicolumn{2}{c}{ Assessment level } \\
\cline { 2 - 3 } SS & Single factor & Multiple factors \\
\hline COD & I \\
DO & II \\
DIN & I \\
Ph & III \\
Pe & I \\
Hg & I \\
As & II \\
$\mathrm{Cu}$ & I \\
$\mathrm{Zn}$ & I \\
$\mathrm{Cd}$ & I \\
$\mathrm{Pb}$ & I \\
$\mathrm{Cr}$ & II \\
\end{tabular}


Table 4. Assessment results of sediment in 2010.

\begin{tabular}{ccc}
\hline \multirow{2}{*}{ Assessment indexes } & \multicolumn{2}{c}{ Assessment level } \\
\cline { 2 - 3 } OC & Single factor & Multiple factors \\
SU & I \\
Pe & I \\
Hg & I \\
$\mathrm{As}$ & I \\
$\mathrm{Cu}$ & I \\
$\mathrm{Zn}$ & I \\
$\mathrm{Cd}$ & I \\
$\mathrm{Pb}$ & $\mathrm{I}$ \\
$\mathrm{Cr}$ & $\mathrm{I}$ \\
\end{tabular}

Table 5. Assessment results of sediment in 2012.

\begin{tabular}{ccc}
\hline \multirow{2}{*}{ Assessment indexes } & \multicolumn{2}{c}{ Assessment level } \\
\cline { 2 - 3 } OC & Single factor & Multiple factors \\
SU & I \\
Pe & I \\
Hg & I \\
As & I & \\
$\mathrm{Cu}$ & II & \\
$\mathrm{Zn}$ & I \\
$\mathrm{Cd}$ & I \\
$\mathrm{Pb}$ & I \\
$\mathrm{Cr}$ & I \\
\hline
\end{tabular}

Table 6. Assessment results of ecology in 2010.

\begin{tabular}{ccc}
\hline \multirow{2}{*}{ Assessment indexes } & \multicolumn{2}{c}{ Assessment level } \\
\cline { 2 - 3 } & Single factor & Multiple factors \\
\hline Chl & II \\
Pp & I & \\
Zp & III & III \\
Be & III \\
Ib & III \\
\hline
\end{tabular}

Table 7. Assessment results of ecology in 2012.

\begin{tabular}{ccc}
\hline \multirow{2}{*}{ Assessment indexes } & \multicolumn{2}{c}{ Assessment level } \\
\cline { 2 - 3 } & Single factor & Multiple factors \\
\hline Chl & II & \\
Pp & III & III \\
Zp & III & \\
Be & IV & \\
Ib & III & \\
\hline
\end{tabular}


Table 8. Comprehensive assessment results.

\begin{tabular}{cc}
\hline Year & Assessment level \\
\hline 2010 & I \\
2012 & II \\
\hline
\end{tabular}

carrying capacity of Ergangdao Island in Tianjin Port. Through the retrospective assessment, the historical development situation in reclamation domain is shown by single factor and multiple factors assessment. The assessment results show that the environmental level is acceptable for marine reclamation. Meanwhile, more researches need be done for obtaining the environmental impact level of marine reclamation, such as hydrodynamics, water exchange, ecological loss and sediment etc.

\section{Acknowledgements}

This work was supported by the National Natural Science Foundation of China (No. 51209110), the project of Science and Technology for Development of Ocean in Tianjin (KJXH2011-17) and the National Nonprofit Institute Research Grants of TIWTE (KJFZJJ2011-01).

\section{References}

Chen, S. Y., \& Li, Y. W. (2005). Water Quality Evaluation Based on Fuzzy Artificial Neural Network. Advances in Water Science, 16, 88-91.

Feng, L. H., Wang, J. Y., \& Zhang, M. Z. (2000). Grey Clustering Evaluation of Environmental Quality. Environmental Protection Science, 26, 37-39.

Fu, B., Li, D. G., \& Wang, M. K. (2011). Review and Prospect on Research of Cloud Model. Application Research of Computers, 28, 420-426.

Li, D. Y., \& Du, Y. (2005). Artificial Intelligence with Uncertainty. Beijing: National Defence Industry Press.

Li, J. Z., \& Liu, X. Z. (2009). The Application Research of the Theory of Uncertainty Set Pair Analysis in Seawater Eutrophication Assessment. Mathematics in Practice and Theory, 39, 84-88.

Li, M. C., Zhang, G. Y., \& You, X. Y. (2010). Set Pair Analysis Method with Nonlinear Membership Function for Sea Water Quality Assessment. Journal of Hebei University of Technology, 39, 81-86.

Li, M. C., Zhang, G. Y., Si, Q., Liang, S. X., \& Sun, Z. C. (2012). Synthetic Assessment Method with Cloud Theory for Marine Water Quality. 2012 International Conference on Sustainable Energy and Environmental Engineering, 298, 821-826.

Pan, F., Fu, Q., \& Liang, C. (2002). Applying Fuzzy Synthesize Judgment in the Study of Water Environment Quality Evaluation. Environment Engineering, 20, 58-61.

Qian, Y. Q. (2006). Macro-Economic Social Evaluation of Water Resources Planning in Dongguang Using Fuzzy Comprehensive Evaluation Method. Zhujiang Modern Construction, 6, 1-4.

Wang, X. (2011). Comprehensive Evaluation of Water Quality Based on Application of Projection Pursuit Model. Ground Water, 33, 5-6.. 